\title{
Differential effects of left and right cerebral vascular accidents on language competency
}

\author{
KAREN L. BRYAN ${ }^{1}$ AND JAMES B. HALE ${ }^{2}$ \\ 'European Institute of Health and Medical Sciences, University of Surrey, Guilford, Surrey, UK \\ ${ }^{2}$ Children's Evaluation and Rehabilitation Center, Albert Einstein College of Medicine, Bronx, NY \\ (ReCeIved December 3, 1999; Revised July 24, 2000; ACCePred August 3, 2000)
}

\begin{abstract}
While language facility was once considered to be the sole province of the "dominant" left hemisphere, clinical and experimental findings suggest the right hemisphere plays an equally important role in many language tasks. To elucidate differential hemispheric language processes, Right Hemisphere Language Battery and Western Aphasia Battery data from left (LHD) and right (RHD) hemisphere cerebral vascular accident (CVA) patients and controls were subjected to multivariate discriminant analysis. The highly significant group differences and overall $95 \%$ classification rate obtained confirms the utility of the dependent measures in differential diagnosis. Results suggest CVA patients experience disparate language deficits, with the LHD group experiencing concordant-convergent language deficits and the RHD group displaying discordant-divergent deficits that interfere with the receptive and expressive language skills necessary for successful social discourse. (JINS, 2001, 7, 655-664.)
\end{abstract}

Keywords: Right hemisphere, Language, Discriminant, Adult CVA

\section{INTRODUCTION}

Ever since 19 th century clinicians recognized that left hemisphere damage (LHD) led to significant language impairment, the right hemisphere has been regarded as subserving the "dominant" left hemisphere in terms of language processing. Early lesion studies revealed that the aphasias were often the result of damage to the left hemisphere language areas (Geschwind, 1972), with little attention paid to the homologous regions of the right hemisphere. Several aphasia test batteries were subsequently developed to assess left hemisphere language functions and examined for their discriminant, predictive, and treatment validity. The measurement of right hemisphere language functions during this period was largely ignored, but as evidence of right hemisphere damage (RHD) patients with "crossed aphasia" began to emerge, clinicians and researchers began to rethink their assumptions that the left hemisphere solely governed language facility (Coppens \& Robey, 1992). Based on studies of RHD patient populations, and hemispheric visual field, dichotic listening, and neuroimaging studies, subsequent research has led to a greater appreciation of interhemispheric processing and expression of linguistic informa-

Reprint requests to: Karen L. Bryan, Ph.D., European Institute of Health and Medical Sciences, University of Surrey, Stag Hill, Guilford, Surrey GU2 7TE, UK. E-mail: k.bryan@surrey.ac.uk tion, and suggests the right hemisphere's contribution is critical for language competence (Van Lancker, 1997).

Language deficits after RHD have been observed in several key areas. Based on the assumption that the right hemisphere was dominant for emotional information (Ross et al., 1997), several studies have demonstrated that RHD patients are deficient in judging and expressing affective speech prosody (Ross, 2000), even after controlling for language content (Lalande et al., 1992). While RHD patients perform poorly on tests of affect processing, emotional content may actually benefit the linguistic performance of those with LHD (Cicero et al., 1999), suggesting hemispheric differences for emotional and verbal communication systems (Barrett et al., 1999). Unlike LHD patients, who have difficulty with temporal speech processing, RHD patient prosodic deficits could be the result of problems with spectral analysis (Robin et al., 1990) and the categorical processing of voicing elements (Simos et al., 1997). Expressively, the speech of RHD patients is characterized by excessive rate (Blonder et al., 1995) and a flat, nonlinear (Behrens, 1989), and monotonous intonational pattern (Mackenzie et al., 1997), referred to as "motor aprosody" (Ross, 1981). These findings are not limited to prosody, however, as RHD patients also experience affective blunting of facial expression, limited eye contact during discourse, and poor word choice when expressing their feelings (Bloom et al., 1990; Mackenzie et al., 1997). 
While these studies suggest affective comprehension and expression may be impaired following RHD, these patients may also have difficulty with breaking down the complex. nature of the stimuli (Bloom, 1994), as evidenced by the other language deficits seen in this population. Clinical and research interests in this area have focused on the ability of RHD patients to draw inferences (Beeman, 1993; Dipper et al., 1997; Wapner et al., 1981), understand metaphor (Critchley, 1991; Mackenzie et al., 1997; Winner \& Gardner, 1987), and appreciate humor (Brownell et al., 1983; Joanette et al., 1990; Winner et al., 1998). RHD patients are especially likely to experience difficulty with most types of nonliteral or figurative speech (Joanette et al., 1990; Van Lancker \& Kempler, 1987), possibly because they cannot revise their literal interpretations of information (Brownell et al., 1986). As a result, patients with RHD have difficulty interpreting proverbs, clichés, idioms, sarcasm, multiple connotations, double meanings, and indirect requests (Giora et al., 2000; Kempler et al., 1999; Richards \& Chiarello, 1997; Ross et al., 1997). Unable to identify the humorous incongruity between premise and punchline (Brownell et al., 1983), RHD patients also have difficulty differentiating between lies and jokes (Winner et al., 1998).

The deficits experienced by individuals following RHD may affect all aspects of language (Beeman \& Chiarello, 1998), but are especially evident when RHD patients process complex lexical-semantic information in social discourse (Molloy et al., 1990, Nicholas \& Brookshire, 1995). Although they are typically not deficient in grammatical knowledge, RHD patients have difficulty with the complex syntactic structures common in social communication (Caplan et al., 1996). They often miss the "gist" or point of social discourse (Hough, 1990), because they have problems processing language in context (Foldi, 1987; Kaplan et al., 1990) and recognizing the functional or pragmatic aspects of language (Joanette \& Ansaldo, 1999; Paradis, 1998). Having a propensity to be overly literal and inflexible, RHD patients seem to have difficulty constructing a semantic representation of discourse, especially when blocking statements shift the course of conversation (Rehak et al., 1992), or they are required to revise preliminary interpretations to integrate new conceptual information (Beeman \& Chiarello, 1998; Stemmer \& Joanette, 1998). When these deficits are combined with an apparent difficulty in recognizing the intentions or perspectives of others (Sabbagh, 1999; Winner et al., 1998), it is not surprising that RHD patients fail to understand the implications of discourse (Brownell et al., 1997; Siegel et al., 1996). Expressively, RHD patients are often inflexible in their use of lexicalsemantic knowledge (Varley, 1995). They have difficulty with retrieval of multiple word meanings (Burgess \& Simpson, 1988) and generating subclasses of semantic categories for during discussion (Joanette \& Goulet, 1988). However, the total word output of RHD patients is apparently not deficient, but is instead filled with trivial, tangential, and unrelated information (Cherney \& Canter, 1993; Myers, 1993). Although individuals with RHD apparently maintain or increase their total verbal output, they often experience qualitative expressive language deficits that lead to ineffectual social discourse

While these findings provide convincing evidence of language deficits following RHD, the cause and nature of the deficits is less clear. There is no consensus on what processing deficits might underlie the clinical features described above, and it may be unrealistic to attribute the many and varying deficits to one cause (Tompkins, 1995). For instance, LHD fluent aphasics display fragmentary, disorganized, and confabulatory discourse (Sandson et al., 1986), but RHD and frontal patients show similar expressive deficits (McDonald, 1993). Both RHD and frontal groups perform similarly when making judgments in social situations (Damasio, 1995) and right orbital-frontal activity has been associated with understanding the perspectives of others (Baron-Cohen et al., 1994). While it has been suggested that RHD patients may be impaired in planning for, or monitoring of, more than one mental model during discourse (Stemmer et al., 1994), these constructs are often associated with executive function (Denckla, 1996) and the dissociation of frontal executive and nonfluent aphasic deficits remains difficult in research and practice (Caspari et al., 1998; Coslett et al., 1991; Gordon, 1998). When taken together with the finding that right frontal lobe activation occurs when multiple associations and interpretations are required (Abdullaev \& Posner, 1997; Posner \& Raichle, 1994), these results suggest it is often difficult to clinically differentiate between frontal and right hemisphere language deficits (McDonald, 1993).

The understanding of the neural basis of complex language processing has been advanced by a number of dichotomous functional descriptors of the left and right hemisphere processes, such as local-global (Delis et al., 1986), microstructural-macrostructural (Glosser, 1993), and finecoarse (Beeman, 1993). As clinicians and researchers moved beyond the naive verbal-nonverbal hemispheric dichotomy, the idea of complementary hemispheric specialization without segregation gained recognition. The left hemisphere may have initial direct access to linguistic information to process it quickly and efficiently (Coney, 1998), but homologous right hemisphere areas are often recruited in response to high task demands or increased linguistic complexity (Belger \& Banich, 1998; Just et al., 1996). Waiting for the callosal channel to open and the left hemisphere to solicit its involvement during high load situations (Belger \& Banich, 1998), the right hemisphere may play more of a supportive "standby" role. However, it has been suggested that language processing occurs simultaneously in both hemispheres, with the contribution of each dependent on the nature of the processing demands (Beeman \& Chiarello, 1998). The right hemisphere maintains activation for multiple meanings of ambiguous words and distant semantic relations; whereas, the left hemisphere is specialized for closely related words, single interpretations, and semantic integration (Chiarello, 1998; Richards \& Chiarello, 1997). The right hemisphere entertains lexical ambiguity (Zaidel 
et al., 1995) through retrospective analysis of the congruence between current and prior language content (Koivisto, 1999), yet the left hemisphere prefers highly probable, predictable, and routinized discourse. Because concordantconvergent answers are required on typical aphasia measures, it is not surprising that the discordant-divergent language deficits seen in RHD patients can go undetected during clinical examination. RHD patients may process the routine, well-known aspects of language and discourse successfully but do not adapt well to the subtle nuances and unpredictable demands of social communication.

While debate about the right hemisphere's role in language competency will undoubtedly continue, the clinical findings have led to a general acceptance among practitioners that RHD communication deficits can occur, and these deficits should be addressed in structured rehabilitation programs (Myers, 1999). Benton and Bryan (1996) suggest that at least $50 \%$ of RHD stroke patients will have language difficulties and these will improve, but not resolve, within a 3 -month period. These are the patients that clinicians need to reliably identify for further assessment and intervention (Klonoff et al., 1990; Myers 1999; Ween et al., 1996). The use of interviews, screening measures, and comprehensive batteries can lead to an accurate identification and diagnosis, the crucial starting point for targeted intervention. Myers (1999) provides an elegant account of a structured screening interview where therapist observations and client responses are examined within an informal discussion context. The interview is complemented by a brief standardized assessment that should be conducted to help establish a diagnosis and an intervention baseline. As was the case with traditional aphasia batteries, diagnostic instruments designed to assess right hemisphere language functions should be developed and scrutinized for their clinical and treatment utility. The Right Hemisphere Language Battery (RHLB; Bryan, 1995) was developed as a brief screening tool for use in comprehensive diagnostic assessment procedures. Used by clinicians in the field (Benton \& Bryan, 1996; Bryan, 1989; Lojek et al., 2000; Mackenzie et al., 1998; Zanini \& Bryan, in press), but also the subject of some criticism (Tompkins, 1995), the RHLB is designed as a deficit-diagnosis rather than process-diagnosis tool. The purpose of this study was to ascertain whether or not the RHLB and Western Aphasia Battery (WAB) could reliably differentiate RHD and LHD patients as evidenced by high group classification rates and group differences on the dependent measures and discriminant functions.

\section{METHODS}

\section{Research Participants}

The sample consisted of 30 right hemisphere vascular damaged (RHD), 30 left hemisphere vascular damaged (LHD), and 30 control participants. Attending neurologists con- ducted mental status examinations of the brain damaged groups and determined participants were alert and in stable medical condition following their first cerebral vascular accident (CVA) 1 to 6 weeks prior to evaluation. Control group participants were recruited from general surgical wards and screened to ensure none had neurological abnormalities at the time of testing. CVA and control patients with dementia were excluded from participation. The three groups were matched for age ( $M$ age range 53.1-56.0), gender (18 male and 12 female), education level, and social background, with Mann-Whitney $U$ tests confirming no difference between groups on these demographic variables (Bryan, 1995). The groups were fairly comparable for occupation status preinsult, with a majority employed in clerical, trade or manual labor positions (18 RHD, $23 \mathrm{LHD}$, and 21 control participants), with the remainder in professional or managerial occupations. All participants were right handed as confirmed by Edinburgh Handedness Inventory (Oldfield, 1971). Using the technique described by Kertesz (1982), CVA patients were administered a $15-\mathrm{cm}$ line bisection task, with 24 RHD participants demonstrating a significant deviation ( $5 \mathrm{~cm}$ or more) to the right and $10 \mathrm{LHD}$ participants showing a significant left deviation. A fairly equal number of RHD $(n=9)$ and LHD ( $n=11)$ participants had hearing impairments as measured by pure tone audiometer, but subjects with significant hearing damage or hearing aids were excluded from the study. Of the $\mathbf{4 2}$ patients who had hemiplegia contralateral to their insults, the RHD participants $(n=26)$ were more likely to receive this diagnosis. When possible, CT scans were obtained for the RHD $(n=15)$ and LHD $(n=16)$ groups, and lesion location (frontal, temporal, parietal, occipital) was confirmed by the attending neuroradiologist. CT scans revealed that many RHD $(n=14)$ and LHD $(n=13)$ participants had more than one lobe affected by the CVA, with three RHD and two LHD patients having experienced damage to three lobes. For the RHD group with CT scans, a majority had damage to the parietal $(n=$ $13)$, temporal $(n=9)$ or frontal $(n=8)$ lobes, with two experiencing damage to the occipital lobe. A majority of the LHD group had parietal ( $n=14)$ and temporal $(n=7)$ damage, but frontal $(n=3)$ and occipital $(n=5)$ damage was less prevalent. Despite these differences, an analysis of variance comparison of participants with large lesions (lesion $M=4073 \mathrm{~mm}^{2}, S D=852$ ) and small lesions (lesion $M=400 \mathrm{~mm}^{2}, S D=144$ ) revealed no significant differences on the dependent measures ( $F$ range .003-1.19, $p$ range $.956-.302$ ) and the dependent variable correlation matrices were comparable across RHD, LHD, and control groups (see Bryan, 1995), suggesting that lesion severity could not account for any group differences found during subsequent analyses.

\section{Procedure}

Participants were recruited from neurology and general surgical units in a large urban university-affiliated hospital in 
the United Kingdom. For all groups, patients were referred for evaluation by their attending physicians and consent was obtained from the patients and/or guardians for the brain damaged groups. All participants were assessed on the Right Hemisphere Language Battery (RHLB; Bryan, 1995) and the Western Aphasia Battery (WAB; Kertesz, 1982) in a quiet hospital room. The order of WAB and RHLB administration was randomized, and no difference between orders was found during RHLB standardization trials (Bryan, 1995). Demographic information was obtained from medical records, patients, and/or family members, and diagnoses were obtained from medical notes. Following data collection, the data were entered into a word processing package for subsequent uploading into the SPSSX computer program. After descriptive and correlational statistics were computed, the RHLB and WAB raw subscale data were subjected to forced-entry discriminant analysis. Following discriminant analysis, Tukey-Kramer post-hoc procedures were used to determine group differences on the dependent measures and latent discriminant functions.

\section{Instrumentation}

\section{Right Hemisphere Language Battery (RHLB)}

The RHLB (Bryan, 1995) is comprised of five subtests, and the Production of Emphatic Stress and the Discourse Analysis tests. Only the five subtests were used in the discriminant analysis. There is a practice item for all subtests and the examiner corrects incorrect practice responses. The Metaphor Picture (MP) subtest (maximum score $=10$ ) consists of 10 sentences in which a physical world adjective is used to describe a psychological state. After hearing the sentence, the examinee must choose from four pictures that include the correct response, a literal response foil, and two foils depicting one aspect of the stimulus. The Written Metaphor (WP) subtest (maximum score $=10$ ) also consists of 10 metaphorical sentences, but the responses are displayed on a card. For the Comprehension of Inferred Meaning (IM) subtest (maximum score $=12$ ), the examinee responds orally to four questions for each of the narrative, conversational, and emotional passages. The questions tap comprehension of information not explicitly stated in the passage. The participant must choose the correct punchline from 10 jokes in the Appreciation of Humour (AH) subtest (maximum score $=$ 10). The AH responses include the correct punchline, two straight ending foils ending in neutral and emotional content, and a surprise ending foil that does not relate to the body of the joke. The 20 -item Lexical Semantic (LS) subtest (maximum score $=20$ ) requires the participant to choose the correct picture representing high-frequency nouns (e.g., car) selected from semantic categories (e.g., transportation). The five foils include two semantic coordinates (e.g., bus, van), a functional associate (e.g., drive), a phonological control (e.g., jar), and a visual control (e.g., shoe). Further information about the technical characteristics of the battery can be found in the RHLB manual (Bryan, 1995).

\section{Western Aphasia Battery (WAB)}

The WAB (Kertesz, 1982) is a well-known aphasia measure designed to evaluate the clinical aspects of language functioning, and it provides an aphasia quotient. Of the WAB measures, the Information (IN), Fluency (FL), Comprehension (CO), Naming (NA), and Repetition (RE) scores were used in discriminant analysis. Technical information about the subtests can be found in the WAB manual (Kertesz, 1982).

\section{RESULTS}

The descriptive statistics and zero-order correlations for the RHLB and WAB measures are reported in Table 1. Correlations within RHLB and WAB batteries were strong, ranging from .50 to .68 for the RHLB and .59 to .94 for the WAB. For cross-battery correlations, only a few measures were modestly correlated, suggesting they measure different constructs. The WAB CO subtest was somewhat related to both $\mathrm{MP}$ and $\mathrm{AH}$, possibly because of the comprehension of verbal content required in both. Similarly, the RHLB LS subtest was related to all WAB subtests except $\Pi$, suggesting that word knowledge and use may be tapped by these measures.

The discriminant analysis used simultaneous entry of all RHLB and WAB variables to determine if the groups could be differentiated by the discriminant functions. With an eigenvalue of 13.57 and a canonical correlation of .97 , the resultant first discriminant function was highly significant $\left(\chi^{2}(20)=283.59, p<.0001\right)$. The second function was also significant $\left(\chi^{2}(9)=86.69, p<.0001\right)$, and the canonical correlation (.83) and eigenvalue (2.25) suggest it differentiated the groups well. The Wilks's $\lambda$ for the first (.021) and second (.308) functions suggests a large portion of group variability could be accounted for by the discriminant functions; however, this suggests function variability is largely shared and the functions are not orthogonal. The correlations between discriminating variables and varimax-rotated canonical discriminant functions, the unstandardized canonical discriminant function coefficients, and the univariate Wilks's $\lambda$ 's and $F$-values for the subtests are reported in Table 2. An examination of the dependent variable correlations with discriminating functions suggests that the WAB subtests serve as measures for the first function; whereas, the RHLB subtests best represent the second function. While the unstandardized function coefficients cannot be interpreted easily, they are useful in calculating function scores for individual subjects. Univariate Wilks's $\lambda$ 's revealed that significantly large portions of variance could be accounted for by the discriminating variables, ranging from $33 \%$ for RHLB MW to $90 \%$ for WAB FL.

Figure 1 depicts the plot of group centroids for the first and second discriminant functions. The visual depiction of extreme group differences was confirmed by a TukeyKramer post-hoc analysis of saved function scores $(p<$ $.05)$. Post-hoc results for the first discriminant function re- 
Table 1. Descriptive statistics and zero-order correlations for study measures

\begin{tabular}{|c|c|c|c|c|c|c|c|c|c|c|}
\hline \multirow[b]{2}{*}{ Measure } & \multicolumn{10}{|c|}{ Two-tailed correlations } \\
\hline & 1. & 2. & 3. & 4. & 5. & 6. & 7. & 8. & 9. & 10. \\
\hline Right Hemisphere Languag & & & & & & & & & & \\
\hline $\begin{array}{l}\text { 1. Metaphor Picture } \\
M=7.80 \\
S D=2.49\end{array}$ & - & $.63 * *$ & $.68 * *$ & $.63 * *$ & $.51^{* *}$ & .17 & .01 & $.22 *$ & .18 & .18 \\
\hline $\begin{array}{l}\text { 2. Metaphor Written } \\
M=8.22 \\
S D=2.32\end{array}$ & & - & $.65^{* * *}$ & $.58 * *$ & $.50 * *$ & .14 & -.01 & .16 & .15 & .19 \\
\hline $\begin{array}{l}\text { 3. Inferential Meaning } \\
\begin{array}{l}M=9.56 \\
S D=2.63\end{array}\end{array}$ & & & - & $.65^{* *}$ & $.55^{* * *}$ & -.12 & -.18 & -.07 & -.06 & -.07 \\
\hline $\begin{array}{l}\text { 4. Appreciation Humor } \\
\qquad \begin{array}{l}M=7.80 \\
S D=2.33\end{array}\end{array}$ & & & & - & $.56 * *$ & .18 & .11 & $.20^{*}$ & .18 & .18 \\
\hline $\begin{array}{l}\text { 5. Lexical Semantic } \\
M=17.99 \\
S D=2.88\end{array}$ & & & & & -- & $.29 * *$ & .06 & $.36^{* *}$ & $.26^{* *}$ & $.27 * *$ \\
\hline Western Aphasia Battery & & & & & & & & & & \\
\hline $\begin{array}{l}\text { 6. Information } \\
\qquad \begin{array}{l}M=9.07 \\
S D=1.70\end{array}\end{array}$ & & & & & & - & $.76^{* *}$ & $.87 * *$ & $.88 * *$ & $.93 * *$ \\
\hline $\begin{array}{l}\text { 7. Fluency } \\
\qquad \begin{array}{l}M=8.56 \\
S D=2.38\end{array}\end{array}$ & & & & & & & - & $.59 * *$ & $.59 * *$ & $.69 * *$ \\
\hline $\begin{array}{l}\text { 8. Comprehension } \\
M=9.51 \\
S D=.77\end{array}$ & & & & & & & & - & $.86^{* *}$ & $.85^{* *}$ \\
\hline $\begin{array}{l}\text { 9. Repetition } \\
\qquad M=9.30 \\
S D=1.55\end{array}$ & & & & & & & & & - & $.94^{* *}$ \\
\hline $\begin{array}{l}\text { 10. Naming } \\
\qquad \begin{array}{r}M=8.80 \\
S D=1.74\end{array}\end{array}$ & & & & & & & & & & - \\
\hline
\end{tabular}

Note. ${ }^{*} p<.01 ; * p<.05$.

vealed that the control $(M=2.12, S D=.18)$ and RHD $(M=2.13, S D=.75)$ groups had higher scores than the LHD group $(M=-6.07, S D=1.74)$, but not each other, suggesting this function measures left hemisphere functioning. As would be expected given the correlations presented in Table 2, the post-hoc analysis revealed the RHD group second function score $(M=-1.95, S D=1.53)$ was lower than those obtained in the LHD $(M=.64, S D=.56)$ and control $(M=1.50, S D=.36)$ groups, but the control group also scored higher than the LHD group. This suggests that the LHD group showed deficits on both the WAB and RHLB, but the RHD group did not perform poorly on the traditional aphasia measure (WAB). Classification results indicated that $95.1 \%$ of the participants were correctly classified by the discriminant functions. While all controls were correctly classified, $90 \%$ of the RHD group and $95.2 \%$ of the LHD group were correctly classified by the discriminant functions. For both CVA groups, all misclassified partici- pants were placed in the control group because their scores did not suggest significant impairment.

As indicated in Table 2, the RHLB and WAB subtests independently discriminated between groups; however, it was unclear whether the measures uniformly differentiated all three groups. Tukey-Kramer post-hoc comparisons for each of the RHLB and WAB subtests are presented in Table 3 . Similar to the discriminant function score results, only the RHLB subtests (except $\mathrm{AH}$ ) differentiated the three groups. For the AH subtest, both the RHD and LHD group were impaired relative to the control group. The RHD and control groups were comparable on the WAB, with the LHD group showing impairment across all subtests. Although the Discourse Analysis was not included in the discriminant analysis, analysis of variance results indicated a difference between the groups $[F(2,88)=186.10, p<.0001]$. Posthoc results suggested the RHD group performed less well on the Discourse Analysis subtest $(M=19.76, S D=6.12)$ 
Table 2. Discriminant function results for predictor variables

\begin{tabular}{|c|c|c|c|c|c|c|}
\hline \multirow[b]{2}{*}{ Variable } & \multicolumn{2}{|c|}{ Fxn correlations } & \multicolumn{2}{|c|}{ Fxn coefficients } & \multirow[b]{2}{*}{ Wilks's $\lambda$} & \multirow[b]{2}{*}{$F^{\mathrm{a}}$} \\
\hline & $\mathrm{LH}$ & $\mathrm{RH}$ & LH & $\mathrm{RH}$ & & \\
\hline \multicolumn{7}{|c|}{ Right Hemisphere Language Battery } \\
\hline Metaphor Picture & .03 & $.57^{*}$ & -.183 & .137 & .57 & 29.56 \\
\hline Metaphor Written & .03 & $.46^{*}$ & .124 & -.155 & .67 & 19.41 \\
\hline Inferential Meaning & -.01 & $.92^{*}$ & -.079 & .538 & .32 & 81.61 \\
\hline Appreciation Humor & .10 & $.57^{*}$ & .095 & 128 & .56 & 30.17 \\
\hline Lexical Semantic & .03 & $.53^{*}$ & .011 & .087 & .60 & 25.81 \\
\hline \multicolumn{7}{|l|}{ Western Aphasia Battery } \\
\hline Information & $.32 *$ & .09 & -.142 & .069 & .44 & 49.61 \\
\hline Fluency & $.83^{*}$ & .09 & 1.550 & -.026 & .10 & 352.90 \\
\hline Comprehension & $.24^{*}$ & .10 & -.333 & -.262 & .57 & 28.83 \\
\hline Repetition & $.21^{*}$ & .06 & .745 & -.228 & .64 & 21.80 \\
\hline Naming & $.27^{*}$ & .12 & -.275 & .214 & .53 & 34.96 \\
\hline
\end{tabular}

Note. Function Coefficients are unstandardized for function computation purposes.

$\mathrm{Fxn}=$ Function; $\mathrm{RH}=$ Right Hemisphere; $\mathrm{LH}=$ Left Hemisphere.

${ }^{\text {a All }} F$ ratios are significant at $p<.0001$

${ }^{*} p<.05$.

than did the LHD $(M=30.73, S D=3.01)$ and control $(M=$ $39.57, S D=1.04$ ) control groups, but the LHD participants were impaired relative to controls.

\section{DISCUSSION}

In an attempt to further explore the characteristics and nature of language deficits following RHD, the purpose of this study was to determine if a battery of language subtests

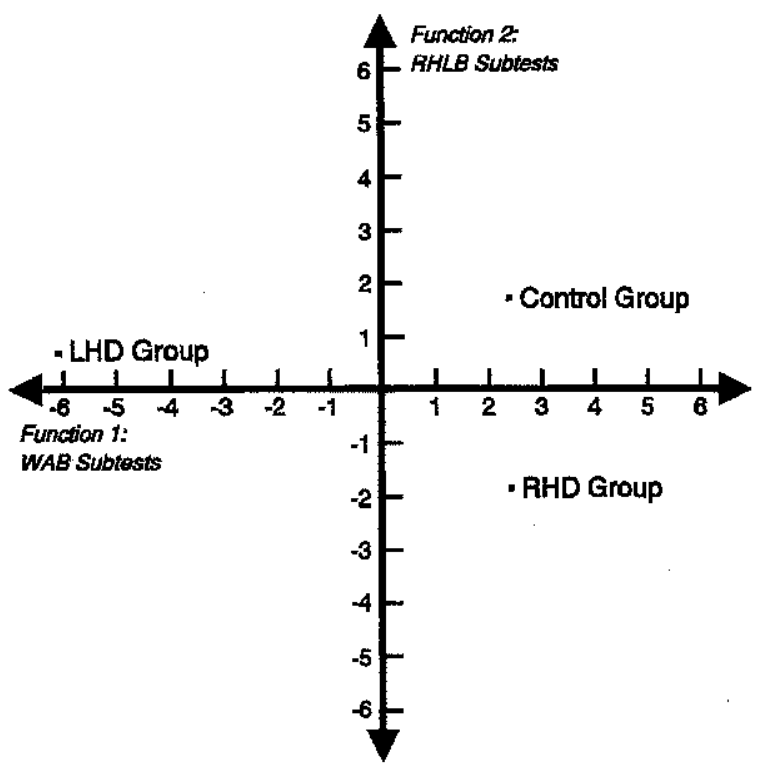

Fig. 1. Discriminant function scores for RHD, LHD, and control groups. from the RHLB and WAB could help differentiate right and left CVA patients and control participants. Although the "dominant" left hemisphere was once considered to be the seat of language functions, clinical and research evidence suggests the right hemisphere processes many types of linguistic information (Beeman \& Chiarello, 1998). Language deficits following RHD have been seen in many areas, including judging and expressing affective speech prosody (Ross, 2000), drawing inferences (Dipper et al., 1997), understanding metaphors (Mackenzie et al., 1997), and appreciating humor (Winner et al., 1998). As they appear to be overly literal and inflexible, RHD patients have difficulty with the pragmatic and figurative aspects of language (Joanette \& Ansaldo, 1999; Paradis, 1998). When combined with a difficulty in recognizing the perspectives of others (Sabbagh, 1999; Winner et al., 1998), these deficits can result in RHD patients missing the gist or point of social discourse (Hough, 1990). While their linguistic deficits may first appear to be subtle, RHD patients should receive comprehensive language evaluations to maximize their success in structured rehabilitation programs (Myers, 1999).

The results of this study suggest the RHLB and WAB provide clinicians with valuable information for differentiating subjects with vascular damage within 6 weeks of the neurological event. The highly significant discriminant functions differentiated subtypes with $95 \%$ accuracy, but only the second function detected differences between all groups. The post-hoc examination of the WAB subtests suggested they identified only the LHD patients, as RHD patients and controls experienced virtually no impairment on these measures. Unlike the results for the WAB, the second discriminant function and RHLB subtests successfully differentiated all three groups. Except for the Appreciation of Humour subtest, RHD patients were impaired relative to LHD and 
Table 3. Tukey-Kramer post-hoc comparisons for dependent measures

\begin{tabular}{|c|c|c|c|c|c|}
\hline Variable & & RHD Group & LHD Group & Control & Effect $t^{2}$ \\
\hline \multicolumn{6}{|c|}{ Right Hemisphere Language Battery } \\
\hline \multirow[t]{2}{*}{ Metaphor Picture } & $M$ & 5.80 & 7.79 & 9.53 & Control $>$ LHD $>$ RHD \\
\hline & $S D$ & 2.54 & 1.95 & .63 & \\
\hline \multirow[t]{2}{*}{ Metaphor Written } & $M$ & 6.60 & 8.15 & 9.67 & Control $>$ LHD $>$ RHD \\
\hline & $S D$ & 2.74 & 1.75 & .71 & \\
\hline \multirow[t]{2}{*}{ Inferential Meaning } & $M$ & 6.80 & 10.52 & 11.60 & Control > LHD > RHD \\
\hline & $S D$ & 2.30 & .96 & .56 & \\
\hline \multirow[t]{2}{*}{ Appreciation Humor } & $M$ & 6.20 & 7.15 & 9.70 & Control > LHD, RHD \\
\hline & $S D$ & 2.58 & 1.46 & .47 & \\
\hline \multirow[t]{2}{*}{ Lexical Semantic } & $M$ & 15.77 & 17.33 & 19.93 & Control $>\mathrm{LHD}>\mathrm{RHD}$ \\
\hline & $S D$ & 3.19 & 3.28 & .25 & \\
\hline \multicolumn{6}{|l|}{ Western Aphasia Battery } \\
\hline \multirow[t]{2}{*}{ Information } & $M$ & 9.63 & 6.30 & 10.00 & Control, RHD > LHD \\
\hline & $S D$ & .49 & 2.45 & .00 & \\
\hline \multirow[t]{2}{*}{ Fluency } & $M$ & 9.77 & 4.60 & 10.00 & Control, RHD > LHD \\
\hline & $S D$ & .43 & 1.65 & .00 & \\
\hline \multirow[t]{2}{*}{ Comprehension } & $M$ & 9.70 & 8.08 & 9.91 & Control, RHD > LHD \\
\hline & $S D$ & .20 & 1.71 & .10 & \\
\hline \multirow[t]{2}{*}{ Repetition } & $M$ & 9.72 & 6.88 & 9.97 & Control, RHD > LHD \\
\hline & $S D$ & .29 & 3.05 & .07 & \\
\hline \multirow[t]{2}{*}{ Naming } & $M$ & 9.23 & 6.06 & 9.75 & Control, RHD > LHD \\
\hline & $S D$ & .39 & 2.76 & .21 & \\
\hline
\end{tabular}

Note. $\mathrm{RHD}=$ Right Hemisphere Damage; $\mathrm{LHD}=$ Left Hemisphere.

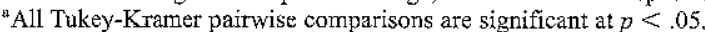

control groups on the RHLB subtests. LHD patients had generally lower scores than control subjects, suggesting the RHLB may not be a "pure" measure of right hemisphere language processes. This is not surprising considering that LHD aphasics would have difficulty with the verbal processing and response demands on the RHLB subtests. Because of the complex nature of language used on the Appreciation of Humour subtest, it may not be as effective as other RHLB subtests in discriminating between RHD and LHD patients. It is possible that the humor on this test is confounded by cultural and personal characteristics, which may not make this subtest an ideal candidate for language screening. Despite this limitation, the results suggest RHD patients have more difficulty with metaphor interpretation, inferential meaning, lexical-semantic information, and social discourse.

In this study the RHD and LHD participants had vascular damage. It is possible that the results described here would not be generalizable to people with nonvascular lesions, where the damage and the pathological processes are different. In addition, caution should be exercised in using the RHLB with tumor patients (Thompson et al., 1997) or those with low levels of education (Mackenzie et al., 1997). In this study, the LHD group consisted almost entirely of individuals with receptive or expressive aphasia; however, not all patients with LHD have aphasia. As we know little about subtle LHD language problems in the absence of aphasia, there is a need to examine LHD nonaphasic and RHD patient differences (Joanette et al., 1990). Similarly, only
$50 \%$ of RHD patients present with language and communication difficulties sufficient to affect day-to-day functioning (Benton \& Bryan, 1996). As such, this figure may be a conservative estimate with RHD patients presenting with very subtle problems not readily detected. Despite these limitations, the results presented here confirm that the RHLB is a useful and reliable initial assessment tool to guide the clinician in diagnostic decision-making and intervention planning. After difficulties are initially identified on the RHLB, Myers (1999) provides a discussion of comprehensive assessments that may be required to confirm diagnostic impressions and develop intensive rehabilitative programs.

A commonality among RHD patients is that they appear to have difficulty with linguistic information that is either complex or ambiguous (Bloom, 1994; Zaidel et al., 1995). This may be related to hemispheric load in the division of mental processing labor, with homologous right hemisphere language areas recruited in times of high demand (Belger \& Banich, 1998). However, the hemispheres appear to simultaneously process information in a different fashion, with the right responsible for coarse processing and the left responsible for fine processing of linguistic information (Beeman \& Chiarello, 1998). Specialized for closely related words, single interpretations, and semantic integration (Richards \& Chiarello, 1997), the left hemisphere processes literal, detailed, routinized, and automatic information. During discourse, RHD patients are likely to use left hemisphere convergent processing to locate and 
select information that is concordant with their existing thoughts but do not maintain the flexibility necessary to revise preliminary interpretations to integrate new conceptual information (Stemmer \& Joanette, 1998) or solve novel problems (Bowden \& Beeman, 1998). This is because they are likely to have difficulty with divergent thinking and fail to recognize novel, incongruent, or discordant information. Not only does this affect their comprehension of social situations, but it also impairs word choice as their expressions are marked by trivial, tangential, and unrelated information (Cherney \& Canter, 1993; Myers, 1993). Consistent with neuroanatomical findings suggesting the right hemisphere specializes in intermodal integration of complex novel stimuli (Goldberg \& Costa, 1981), those with RHD are likely to overutilize the left hemisphere's well-routinized codes or scripts to process and respond to social discourse, often failing to remain flexible enough to adapt to the unique demands of an interpersonal exchange.

Clinicians should examine RHD patients for these characteristic patterns of language performance during comprehensive evaluations yet recognize that not all patients will exhibit the same deficits (Tompkins, 1995) or display significant language impairments (Benton \& Bryan, 1996). Thorough examination of individual clinical cases is needed to explore different types of RHD language and communication problems and the nature of the deficits to be understood. Future research could reveal a characteristic profile of linguistic deficits following RHD and whether this profile is generalizable to different patients with different types of lesions. To fully understand the complementary nature of left and right hemisphere language processes, detailed neuroimaging studies may be necessary to reveal information about lesion location, clinical presentation, and lateralization of function (Khatri \& Hier, 2000). Investigators could also attempt to differentiate receptive from expressive language deficits in this population and determine whether RHD language subtypes have disparate etiologies and rehabilitative courses. While research and clinical evidence may further differential diagnosis of RHD language deficits, the results presented here confirm the utility of the WAB and RHLB as part of a comprehensive language evaluation of CVA patients. When a RHD patient presents with history suggestive of language impairment, careful clinical examination of all aspects of language processing should be undertaken prior to developing a systematic rehabilitative program designed to optimize the patient's recovery of function.

\section{REFERENCES}

Abdullaev, Y.G. \& Posner, M.I. (1997). Time course of activating brain areas in generating verbal associations. Psychological Science, 8, 56-59.

Baron-Cohen, S., Ring, H., Moriarty, J., Schmitz, B., Costa, D., \& Eli, P. (1994). The brain basis of theory of mind: The role of orbito-frontal region. British Journal of Psychiatry, 165, $640-649$.
Barrett, A.M., Crucian, G.P., Raymer, A.M., \& Heilman, K.M. (1999). Spared comprehension of emotional prosody in a patient with global aphasia. Neuropsychiatry, Neuropsychology, and Behavioral Neurology, 12, 117-120.

Beeman, M. (1993). Semantic processing in the right hemisphere may contribute to drawing inferences from discourse. Brain and Language, 44, 80-120.

Beeman, M.J. \& Chiarello, C. (1998). Complementary right- and left-hemisphere language comprehension. Psychological Science, $7,2-7$.

Behrens, S.J. (1989). Characterizing sentence intonation in a right hemisphere-damaged population. Brain and Language, 37, $181-200$

Belger, A. \& Banich, M.T. (1998), Costs and benefits of integrating information between the cerebral hemispheres: A computational perspective. Neuropsychology, 12,380-398.

Benton, E. \& Bryan, K. (1996). Incidence of language disorder after right hemisphere CVA. International Journal of Rehabilitation Research, 19, 47-54.

Blonder, L.X., Pickering, J.E., Heath, R.L., Smith, C.D., \& Butler, S.M. (1995). Prosodic characteristics of speech pre- and postright hemisphere stroke. Brain and Language, 51, 318-335.

Bloom, R.L. (1994). Hemispheric responsibility and discourse production: Contrasting patients with unifateral left and right hemisphere damage. In R.L. Bloom, L.K. Obler, S. De Santi, \& J.S. Ehrlich (Eds.), Discourse analysis and applications: Studies in adult clinical populations (pp. 81-94). Hillsdale, NJ: Erlbaum.

Bloom, R.L., Borod, J.C., Obler, L., \& Koff, E. (1990). A preliminary characterization of lexical emotional expression in right and left brain-damaged patients. International Journal of Neuroscience, $55,71-80$.

Bowden, E.M. \& Beeman, M.J. (1998). Getting the right idea: Semantic activation in the right hemisphere may help solve insight problems. Psychological Science, 9, 435 -440.

Brownell, H.H., Michel, D., Powelson, J.A., \& Gardner, H. (1983). Surprise but not coherence: Sensitivity to verbal humor in right hemisphere patients. Brain and Language, 18, 20-27.

Brownell, H., Pincus, D., Blum, A., Rehak, A., \& Winner, E. (1997). The effects of right-hemisphere brain damage on patients' use of terms of personal reference. Brain and Language, 57, 60-79.

Brownell, H.H., Potter, H.H., Bihrle, A.M., \& Gardner, H. (1986). Inference deficits in right brain-damaged patients, Brain and language, 29, 310 321 .

Bryan, K. (1995). The Right Hemisphere Language Battery (2nd ed.). London: Whurr.

Bryan, K. (1989). Language prosody and the right hemisphere. Aphasiology, 3, 285-299.

Burgess, C. \& Simpson, G. (1988). Cerebral hemispheric mechanisms in the retrieval of ambiguous word meanings. Brain and Language, 33, 86-103.

Caspari, I., Parkinson, S.R., LaPointe, L.L., \& Katz, R.C. (1998). Working memory and aphasia. Brain and Cognition, 37, 205-223.

Caplan, D., Hildebrandt, N., \& Makris, N. (1996). Location of lesions in stroke patients with deficits in syntactic processing in sentence comprehension. Brain, 119, 933-949.

Cherney, L.R. \& Canter, G.J. (1993). Informational content in the discourse of patients with probable Alzheimer's disease and patients with right brain damage. In M.L. Lemme (Ed.), Clinical aphasiology (pp. 123-134). Austin, TX: Pro-Ed.

Chiarello, C. (1998). On codes of meaning and the meaning of codes: Semantic access and retrieval within and between hemi- 
spheres. In M. Beeman \& C. Chiarello (Eds.), Right hemisphere language comprehension: Perspectives from cognitive neuroscience (pp. 141-160). Mahwah, NJ: Erlbaum.

Cicero, B.A., Borod, J.C., Santschi, C., Erhan, H.M., Obler, L.K., Agosti, R.M., Welkowitz, J., \& Grunwald, I.S. (1999). Emotional versus nonemotional lexical perception in patients with right and left brain damage. Neuropsychiatry, Neuropsychol ogy, and Behavioral Neurology, 12, 255-264.

Coney, J. (1998). Hemispheric priming in a reading task. Brain and Language, 62, 34-50.

Coppens, P. \& Robey, R.R. (1992). Crossed aphasia: New perspectives. Aphasiology, 6, 585-596.

Coslett, H.B., Bowers, D., Verfaellie, M., \& Heilman, K.M. (1991). Frontal verbal amnesia: Phonological amnesia. Archives of Neurology, 48, 949-955.

Critchley, E.M. (1991). Speech and the right hemisphere. Behavioral Neurology, 4, 143-151.

Damasio, A.R. (1995). Descartes'error: Feeling, reason, and the human brain. New York: G.P. Putnam's Sons.

Delis, D., Robertson, L., \& Efron, R. (1986). Hemispheric specialization of memory for visual hierarchical stimuli. Neuropsychologia, 24, 205-214.

Denckla, M.B. (1996). A theory and model of executive function: A neuropsychological perspective. In G.R. Lyon \& N.A. Krasnegor (Eds.), Attention, memory, and executive function (pp. 263-278). Baltimore: Brookes.

Dipper, L., Bryan, K., \& Tyson, J. (1997). Bridging inference and relevance theory: An account of right hemisphere inference. Clinical Linguistics and Phonetics, 11, 213-228.

Foldi, N.S. (1987), Appreciation of pragmatic interpretation of indirect commands: Comparison of right and left hemispheredamaged patients. Brain and Language, 31, 88-108.

Geschwind, N. (1972). Language and the brain. Scientific American, $226,76 \cdots 83$.

Giora, R., Zaidel, E., Soroker, N., Batori, G., \& Kasher, A. (2000). Differential effect of right- and left-hemisphere damage on understanding sarcasm and metaphor. Metaphor and Symbol, $15,63-83$.

Glosser, G. (1993). Discourse production patterns in neurologically impaired and aged populations. In H.H. Brownell \& Y. Joanette (Eds.), Narrative discourse in neurologically impaired and normal aging adults (pp. 191-212). San Diego, CA: Singular.

Goldberg, E. \& Costa, L.D. (1981). Hemispheric differences in the acquisition and use of descriptive systems. Brain and Language, 14, 144-173.

Gordon, J.K. (1998). The fluency dimension of aphasia. Aphasiology, $12,673 \cdots 688$.

Hough, M. (1990). Narrative comprehension in adults with right and left hemisphere brain-damage. Brain and Language, 38 , 253-277.

Joanette, Y. \& Ansaldo, A.I. (1999). Clinical note: Acquired pragmatic impairments and aphasia. Brain and Language, 68, 529-534.

Joanette, Y. \& Goulet, P. (1988). Word-naming in right-braindamaged subjects. In C. Chiarello (Ed.), Right hemisphere contributions to lexical semantics (pp. 1-18). New York: Springer-Verlag.

Joanette, Y., Goulet, P., \& Hannequin, D. (1990). Right hemisphere and verbal communication. New York: Springer-Verlag.

Just, M.A., Carpenter, P.A., Keller, T.A., Eddy, W.F., \& Thulborn,
K.R. (1996). Brain activation modulated by sentence comprehension. Science, 274, 114-116

Kaplan, J.A., Brownell, H.H., Jacobs, J.R., \& Gardner, H. (1990). The effects of right hemisphere damage on the pragmatic interpretation of conversational remarks. Brain and Language, 38, 122-134.

Kempler, D. Van Lancker, D., Marchman, V., \& Bates, E. (1999). Idiom comprehension in children and aduits with unilatera brain damage. Developmental Neuropsychology, 15, 327-349.

Kertesz, A. (1982). Western Aphasia Battery. San Antonio, TX The Psychological Corporation.

Khatri, P. \& Hier, D.B. (2000). Imaging aphasia: The coming paradigm shift. Brain and Cognition, 42, 60--63.

Klonoff, P.S., Sheperd, J.C., O'Brien, K.P., \& Chiapello, D.A (1990). Rehabilitation and outcomes of right hemisphere stroke patients: Challenges to traditional diagnostic and treatment methods. Neuropsychology, 4, 147-163.

Koivisto, M. (1999). Hemispheric dissociations in controlled lexical-semantic processing. Neuropsychology, 13, 488-497.

Lalande, S., Braun, C.M., Charlebois, N., \& Whitaker, H.A. (1992). Effects of right and left hemisphere cerebrovascular lesions on discrimination of prosodic and semantic aspects of affect in sentences. Brain and Language, 42, 165-186.

Lojek, E., Scotnicka, M., \& Bryan, K. (2000). The set of neuropsychological tests for the assessment of language disorders after right hemisphere damage - preliminary results. Journal of the Polish Neuropsychological Society and Society of Neurosurgeons, 34, 71-81.

Mackenzie, C., Begg, T., Brady, M., \& Lees, K.R. (1997). The effects on verbal communication skills of right-hemisphere stroke in middle age. Aphasiology, 11, 929-945.

McDonald, S. (1993). Viewing the brain sideways? Frontal versus right hemisphere explanations of non-aphasic language disorders. Aphasiology, 7, 535-549.

Molloy, R., Brownell, H.H., \& Gardner, H. (1990). Discourse comprehension by right hemisphere stroke patients: Deficits of production and revision. In Y. Joanette \& H.H. Brownell (Eds.), Discourse ability and brain damage: Theoretical and empirical perspectives (pp. 113-130). New York: Springer-Verlag.

Myers, P.S. (1993). Narrative expressive deficits associated with right hemisphere damage. In H.H. Brownell \& Y. Joanette (Eds.), Narrative discourse in neurologically impaired and normal aging adults (pp. 279-298). San Diego, CA: Singular.

Myers, P.S. (1999). Right hemisphere damage. Disorders of com munication and cognition. New York: Springer-Verlag.

Nicholas, L.E. \& Brookshire, R.H. (1995). Presence, completeness, and accuracy of main concepts in the connected speech of non-brain-damaged adults and adults with aphasia. Journal of Speech and Hearing Research, 38, 145-157.

Oldfield, R.C. (1971). The assessment and analysis of handedness: The Edinburgh Inventory. Neuropsychologia, 9, 97-113.

Paradis, M. (1998). The other side of language: Pragmatic competence. Journal of Neurolinguistics, 11, 1-10.

Posner, M. \& Raichle, M. (1994). Images of mind. New York: Scientific American Library.

Rehak, A., Kaplan, J.A., \& Gardner, H. (1992). Sensitivity to conversational deviance in right-hemisphere damaged patients. Brain and Language, 42, 203-217.

Richards, L. \& Chiarello, C. (1997). Activation without selection: Parallel right hemisphere roles in language and intentional movement? Brain and Language, 57, 151-178.

Robin, D.A., Tranel, D., \& Damasio, H. (1990). Auditory percep- 
tion of temporal and spectral events in patients with focal left and right cerebral lesions, Brain and Language, 39, 539-555.

Ross, E.D. (1981). The aprosodias: Functional-anatomic organization of the affective components of language in the right hemisphere. Annals of Neurology, 38, 561-589.

Ross, E.D. (2000). Affective prosody and the aprosodias. In M.M. Mesulam (Ed.), Principles of behavioral and cognitive neurology (2nd ed., pp. 316-331). New York: Oxford University Press.

Ross, E.D., Thompson, R.D., \& Yenowsky, J. (1997). Lateralization of affective prosody in brain and the callosal integration of hemispheric language functions. Brain and Language, 56, $27-54$.

Sabbagh, M. A. (1999). Communicative intentions and language: Evidence from right-hemisphere damage and autism. Brain and Language, $70,29-69$.

Sandson, J., Albert, M.L., \& Alexander, M.P. (1986). Confabulation in aphasia. Cortex, 22, 621- 626.

Siegel, M., Carrington, J. \& Radel, M. (1996). Theory of mind and pragmatic understanding following right hemisphere damage. Brain and Language, 53, 40-50.

Simos, P.G., Molfese, D.L., \& Brenden, R.A. (1997). Behavioral and electrophysiological indices of voicing-cue discrimination: Laterality patterns and development. Brain and Language, 57, 122-150.

Stemmer, B., Giroux, F., \& Joanette, Y. (1994). Production and evaluation of requests by right hemisphere brain-damaged individuals. Brain and Language, 47, 1-31.

Stemmer, B. \& Joanette, Y. (1998). The interpretation of narrative discourse of brain-damaged individuals within the framework of a multilevel discourse model. In M. Beeman \& C. Chiarello (Eds.), Right hemisphere language comprehension: Perspectives from cognitive neuroscience (pp. 329-348). Mahwah, NJ: Lawrence Erlbaum.
Thompson, A.M., Taylor, R., Fraser, D., \& Whittle, I.R. (1997). The utility of the Right Hemisphere Language Battery in patients with brain tumours. European Journal of Disorders of Communication, 32, 325-332.

Tompkins, C. (1995). Right hemisphere communication disorders. Theory and management. San Diego, CA: Singular.

Van Lancker, D. (1997). Rags to riches: Our increasing appreciation of cognitive and communicative abilities of the human right cerebral hemisphere. Brain and Language, 57, 1-11.

Van Lancker, D.R. \& Kempler, D. (1987). Comprehension of familiar phrases by left- and right-hemisphere damaged patients. Brain and Language, 32, 265-277.

Varley, R. (1995). Lexical-semantic deficits following right hemisphere damage: Evidence from verbal fluency tasks. European Journal of Disorders of Communication, 30, 362-371.

Wapner, W., Hamby, S., \& Gardner, H. (1981). The role of the right hemisphere in apprehension of complex linguistic materials. Brain and Language, 14, 15-32.

Ween, J.E., Alexander, M.P., D'Eposito, M., \& Roberts, M. (1996). Factors predictive of stroke outcome in a rehabilitation setting. Neurology, 47, 388-392.

Winner, E., Brownell, H., Happe, F., Blum, A., \& Pincus, D. (1998). Distinguishing lies from jokes: Theory of mind deficits and discourse interpretation in right hemisphere brain-damaged patients. Brain and Language, 62, 89-106.

Winner, E. \& Gardner, H. (1987). The comprehension of metaphor in brain damaged patients. Brain, 100, 717-729.

Zaidel, D.W., Zaidel, E., Oxbury, S.M., \& Oxbury, J.M. (1995). The interpretation of sentence ambiguity in patients with unilateral focal brain injury. Brain and Language, 51, 458-468.

Zanini, S. \& Bryan, $\mathrm{K}$. (in press). La batteria del linguaggio dell emisfero destro (Ba. L.E.D.) [The Right-Hemisphere Language Battery]. Bologna, Italy: Sistemi Elettromedicali 